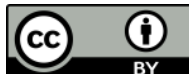

\title{
Compartilhamento e proteção do conhecimento: um estudo realizado em uma empresa de conhecimento intensivo do setor sucroenergético
}

Rogerio Salles Loureiro

Mestre em Administração - Universidade Metodista de Piracicaba - PPGA/UNIMEP

Daniel Basso Polezi

Administrador, mestre em Educação e doutorando em Administração pelo PPGA da Universidade Metodista de Piracicaba

Dalila Alves Corrêa

Administradora. Doutora e docente do
PPGA/UNIMEP - Universidade
Piracicaba

Érica Cristiane Belon Galvão

Doutoranda em Administração do PPGA Universidade Metodista de Piracicaba

Sergio Ricardo Siani

Mestrando em Administração pelo PPGA da Universidade Metodista de Piracicaba

http://dx.doi.org/10.1590/1981-5344/3247

A literatura especializada em gestão do conhecimento prioriza a perspectiva compartilhamento, e em menor proporção, a proteção, além do que, via de regra, são dimensões tratadas de modo fragmentado. Nesse contexto, identifica-se uma lacuna de produção bibliográfica. Na prática gerencial essa realidade também é observada constituindo num dilema para os gestores. $O$ objetivo do artigo consiste em analisar $o$ compartilhamento e proteção do conhecimento numa empresa de inovação, do setor sucroenergético. Trata-se de um estudo qualitativo, de natureza descritiva $e$ 
exploratória. Para o levantamento de dados foi utilizada a entrevista semiestruturada e individual, aplicada a um grupo de gestores de pesquisa e desenvolvimento, e para os responsáveis pelas áreas de recursos humanos, propriedade intelectual e gestão de informações da empresa. Utilizou-se também a análise documental, observação direta e observação participante. $O$ estudo mostrou que os gestores se utilizam de diversas ferramentas e práticas para compartilhar e proteger conhecimento sem o amparo de uma política organizacional orientadora das decisões sobre o que compartilhar e o que proteger. Diante desta realidade, confirmou-se a existência do dilema gerencial, na medida em que os gestores reconhecem a fragilidade a que se está exposto um dos aspectos mais críticos da vantagem competitiva organizacional, o ativo conhecimento.

Palavras-chave: Conhecimento organizacional. Compartilhamento de conhecimento. Proteção de conhecimento. Setor sucroenergético.

\section{Knowledge Sharing and Protection: a Study Carried Out in a Innovation Company of the Sugar-energy Sector}

The literature specialized in knowledge management prioritizes a sharing perspective and also, a protection perspective in a lower content. But these dimensions have been treated in a fragmented way. In this context, a bibliographic production gap has been identified. In management practice this reality is also observed, and constitutes a dilemma for managers. The objective of the study is to analyze the sharing and protection knowledge in a innovation company of sugar-energy division. This is a qualitative, descriptive and exploratory study. The data collection was built with semi-structured and individual interview. It was applied to a group of managers of research development departmentall human resources department the intellectual property and information management of the company. Documentary analysis, direct observation and participant observation were also used. The study has showed that managers use a variety of tools and practices to protect and share knowledge without the support of organizational policy that guides 
decisions about what to share and protect. In this reality, the existence of managerial dilemma was confirmed, as managers recognize a fragility in which case one is exposed to one of the most critical of organizational competitive advantage, the knowledge.

Keywords: Organizational knowledge. Knowledge sharing. Knowledge protection. Sugar-energy sector.

Recebido em 04.08.2017 Aceito em 23.05.2018

\section{Introdução}

Não restam dúvidas acerca da importância do conhecimento organizacional (IYER; RAVINDRAN, 2013). O tema ganhou notoriedade no fim da década de 1980, recebendo maior atenção nos anos de $1990 \mathrm{com}$ as abordagens de Prahalad e Hamel (1990), Drucker (1991), Nonaka (1991), Grant (1996), Nonaka e Takeuchi (1997), Stewart (1998) e Davenport e Prusak (1998). Fica compreendido que a experiência condensada, os valores, a informação contextual, o insight, são fragmentos que proporcionam a estrutura para a incorporação experiências e informações. Ele possui origem e é aplicado na mente dos conhecedores. Nas organizações, costuma estar embutido em documentos, rotinas, processos, práticas e normas. Assim, não são estanques e fazem parte de um contínuo no qual o desempenho eficaz do trabalho do conhecimento é fundamental para o desempenho (DAVENPORT, 2015). O modo como é compartilhado e protegido são também temas de grande preocupação nas organizações e amplamente pesquisados, todavia pouco explorados em conjunto. Ou seja, há uma tendência de considerar o tema de maneira fragmentada.

Nesse contexto, o objetivo desse artigo foi investigar como os gestores de um centro de pesquisa e desenvolvimento da cana de açúcar, líder mundial nesse tipo de pesquisa, lidam com o conhecimento organizacional em situações de compartilhar e proteger. O tema surgiu como interesse em conhecer os limites e possibilidades do assunto no referido contexto, buscando também identificar a importância que os gestores atribuem ao conhecimento organizacional já que se trata de uma organização intensiva em conhecimento, e referência na atividade de pesquisa desse setor. Procurou-se observar também a existência de dilema na prática gerencial relacionado às decisões sobre o que compartilhar e o que proteger, bem como a presença de uma política da organização voltada para essa finalidade. As políticas possuem grande influência na segurança do conhecimento (TEIXEIRA et al., 2012) assim como para o compartilhamento, como notado neste estudo. As empresas, de modo geral entendem que a importância em proteger o conhecimento 
supera a atual presença de dispositivos voltados para a proteção conhecimento (OLIVEIRA et al., 2013).

Desse modo, o estudo promove uma discussão sobre essa questão, que se mostra aparentemente simples, mas guarda em si dilemas e ambiguidades.

\section{Referencial teórico}

A partir de 1991 os gastos com tecnologia da informação das empresas norte-americanas superaram os gastos com tecnologia de produção (STEWART, 1998), sendo observável que a vantagem competitiva sustentável está baseada na informação, conhecimento, inovação e educação continuada (ALVARENGA NETO, 2008). No cenário da crise americana de 2008, o mercado de tecnologia da informação foi muito menos afetado naquele país do que outros setores (ROJKO; LESJAK; VEHOVAR, 2011). Assim, nota-se que o conhecimento e seu fluxo são percebidos como fundamentais para a sobrevivência das empresas, sendo essencial o estudo de como o conhecimento é gerido, mal gerido e não gerido nas organizações (DAVENPORT, 2015).

Buscando diferenciar conhecimento de informação, Nonaka e Takeuchi (1997) definem conhecimento como função de uma atitude, perspectiva ou intenção específica e que diz respeito a crenças e compromissos.

A transformação de informação em conhecimento, sob a ótica de Davenport e Prusak (1998) ocorre através dos questionamentos de comparação, consequências, conexões e conversação.

Choo (2006) observa o uso estratégico da informação em três arenas distintas: (a) dar sentido às mudanças do ambiente externo; (b) gerar novos conhecimentos através da criação, organização e processamento da informação, e (c) tomar decisões através da busca e avaliação das informações.

De comum as definições sobre "conhecimento" incluem a perspectiva evolutiva sobre o uso da informação, cabendo resgatar a abordagem de Davenport e Prusak (1998, p. 6) que o descrevem como sendo uma "mistura fluida de experiência condensada, valores, informação contextual e insight experimentado, a qual proporciona uma estrutura para a avaliação e incorporação de novas experiências e informações. Ele tem origem e é aplicado na mente dos conhecedores".

Nesse artigo, a definição de conhecimento organizacional adotada consiste em reconhece-lo enquanto ativo de conhecimento individual e coletivo que a organização pode utilizar para realizar suas tarefas. Os ativos de conhecimento também incluem os dados e as informações sobre os quais se constroem o conhecimento individual e organizacional (DAVENPORT, 2015) e trata-se de uma competência organizacional própria de cada empresa (SVEIBY, 1998). 
A classificação mais conhecida de conhecimento é a sua separação em tácito e explícito estabelecida por Michael Polanyi em 1966. O primeiro é espontâneo, intuitivo, experimental, conhecimento cotidiano, pessoal, difícil de ser formalizado e de ser compartilhado, sendo exemplos os palpites, intuições, insights e know-how. O conhecimento explícito é aquele codificado, expresso em palavras, números, sons, fórmulas matemáticas, regras e especificações (CHOO, 2006; NONAKA; TAKEUCHI, 2008). Ele é mais fácil de ser compartilhado e transmitido entre as pessoas.

Uma ampliação da separação do conhecimento em dois tipos (tácito e explícito) é dada por Choo (2006) que inclui um terceiro tipo: o conhecimento cultural que consiste em estruturas cognitivas e emocionais que habitualmente são usadas pelos membros da organização para perceber, explicar, avaliar e construir a realidade.

Uma outra classificação do conhecimento (VAN DER BERG, 2013) é dada em 3 tipos: Tácito, Codificado e Encapsulado. Os três são conhecimentos originados do pensamento, da reflexão ou da experiência. O primeiro constitui-se na base para a derivação. O segundo é expresso como informação através da utilização de símbolos e o terceiro é embutido no desenho ou funcionalidade dos produtos. Esse autor afirma que, na maioria das vezes, a vantagem competitiva é obtida pela mistura destes 3 tipos. As classificações sugerem que as mesmas se constituem em subdivisões do conhecimento tácito ou do explícito, conforme ilustra o Quadro 1.

Quadro 1 - Tipos de conhecimento

\begin{tabular}{c|c|c|c}
\hline $\begin{array}{c}\text { Polanyi (1966) e } \\
\text { Nonaka; Takeuchi (1997) }\end{array}$ & Nonaka; Takeuchi (2008) & Choo (2006) & \multirow{2}{*}{ Van der Berg (2013) } \\
\hline \hline \multirow{2}{*}{ Tácito } & Tácito - Técnico & Tácito & Tácito \\
\cline { 2 - 3 } & Tácito - Cognitivo & Cultural & Codificado \\
\cline { 2 - 4 } Explícito & Explícito & Explícito & Encapsulado \\
\hline
\end{tabular}

Fonte: Elaborado pelos autores.

A parte da classificação de tipos de conhecimento, autores como Grant (1996), Chai et al. (2003) e Kogut e Zander (1992) buscaram definir as dimensões do conhecimento. Estas dimensões, que auxiliam a entender o conhecimento no ambiente organizacional, foram agrupadas por Nakano e Fleury (2005), conforme mostra o Quadro 2.

Quadro 2 - Dimensões do conhecimento

\begin{tabular}{l|l}
\hline \multicolumn{1}{c|}{ Dimensão } & \multicolumn{1}{c}{ Descrição } \\
\hline \hline Codificabilidade & Grau no qual o conhecimento pode ser transformado em um conjunto de regras e relações \\
\hline Complexidade & Definido indiretamente pelo esforço necessário para codificar o conhecimento \\
\hline Transferibilidade & Grau em que o conhecimento pode ser transferido sem degradação \\
\hline Agregabilidade & Grau em que o conhecimento pode ser combinado \\
\hline Apropriabilidade & Grau pelo qual o detentor do conhecimento pode obter retorno \\
\hline $\begin{array}{l}\text { Dependência do } \\
\text { contexto }\end{array}$ & $\begin{array}{l}\text { Grau em que o conhecimento é específico para um determinado contexto sociocultural, político, } \\
\text { econômico e financeiro. }\end{array}$ \\
\hline
\end{tabular}

$$
\text { Fonte: NAKANO; FLEURY (2005). }
$$


A observação destas dimensões em conjunto com a espiral do conhecimento (NONAKA; TAKEUCHI, 1997) é importante para verificar quais conhecimentos podem ser compartilhados, quão fácil é este compartilhamento e quanto dependente deste conhecimento a organização se encontra.

A abordagem estratégica conceituada por Barney (1991) questiona o modelo de Porter (1981) que afirmou que os recursos diferenciais de uma empresa são móveis e que empresas dentro de um mesmo mercado podem obter os mesmos recursos estratégicos. Esta abordagem define que os recursos estratégicos controlados por uma empresa podem ser diferentes de outra empresa do mesmo mercado e que estes recursos, que geram o diferencial competitivo, podem não ser perfeitamente móveis entre organizações. Os recursos podem ser agrupados nas categorias de Capital Físico, Humano ou Organizacional.

No Quadro 3 são comparadas as 4 condições definidas por Barney (1991) para um recurso ser de difícil imitação. Como recurso de difícil imitabilidade as questões referentes ao compartilhamento e proteção deste importante ativo organizacional se tornam importantes e necessitam ser discutidas em maior profundidade.

\section{Quadro 3 - Analogia do conhecimento organizacional}

\begin{tabular}{|c|c|c|}
\hline \multicolumn{2}{|c|}{$\begin{array}{c}\text { Condição para a difícil imitabilidade de } \\
\text { um recurso (BARNEY, 1991) }\end{array}$} & \multirow[t]{2}{*}{ Analogia para o Conhecimento Organizacional como recurso } \\
\hline Condição & Descrição & \\
\hline $\begin{array}{l}\text { Dependência de } \\
\text { condições históricas } \\
\text { únicas }\end{array}$ & $\begin{array}{l}\text { Significa que a } \\
\text { obtenção no recurso } \\
\text { depende do caminho } \\
\text { que foi seguido para } \\
\text { obtê-lo. }\end{array}$ & $\begin{array}{l}\text { O conhecimento é gerado a partir das interações com o ambiente e como } \\
\text { cada ser humano e cada organização tem uma história própria, ele é } \\
\text { totalmente dependente do caminho seguido para cria-lo (CHOO, 2006). }\end{array}$ \\
\hline Ambiguidade causal & $\begin{array}{l}\text { É quando não se } \\
\text { consegue uma ligação } \\
\text { direta entre a } \\
\text { vantagem competitiva } \\
\text { e o recurso }\end{array}$ & $\begin{array}{l}\text { A relação do conhecimento proprietário e controlado pela empresa com } \\
\text { sua vantagem competitiva nem sempre é conhecido. Davenport e Prusak } \\
\text { (1998) expressam bem esta dificuldade quando citam a célebre frase do } \\
\text { ex-presidente da HP, Lew Platt: "Se a HP soubesse o que a HP sabe, } \\
\text { nossa rentabilidade seria três vezes maior". }\end{array}$ \\
\hline $\begin{array}{l}\text { Complexidade } \\
\text { social }\end{array}$ & $\begin{array}{l}\text { Os recursos rão } \\
\text { fenômenos sociais } \\
\text { complexos e, por } \\
\text { isso, difíceis de serem } \\
\text { imitados. }\end{array}$ & $\begin{array}{l}\text { É evidente a questão social do conhecimento e sua complexidade. Choo } \\
\text { (2006, p.351), define o conhecimento organizacional como "...um } \\
\text { contínuo processo de construção social e ação coletiva incorporado nas } \\
\text { tarefas, nos relacionamentos e instrumentos da organização" }\end{array}$ \\
\hline Substitutibilidade & $\begin{array}{l}\text { Um recurso não pode } \\
\text { ser substituído por } \\
\text { outro semelhante. }\end{array}$ & $\begin{array}{l}\text { O conhecimento é específico ao contexto e depende da situação } \\
\text { (NONAKA; TAKEUCHI, 2008), por isso é difícil de ser substituído por } \\
\text { outro conhecimento. Em outras palavras, o conhecimento é criado pela } \\
\text { interação social entre as pessoas (NONAKA; TAKEUCHI, 2008) mas } \\
\text { não substituído. }\end{array}$ \\
\hline
\end{tabular}

Fonte: Elaborado pelos autores a partir de BARNEY (1991).

Percebe-se que a decisão entre a manutenção da segurança e a melhoria de usabilidade dos sistemas de informação continua a ser um tema importante entre os gestores e acadêmicos (DHILLON et al., 2016). No entanto, poucos são os estudos que se propuseram avaliar, em conjunto, os processos de compartilhamento e proteção do conhecimento em empresas de inovação. A necessidade de desenvolvimento rápido de produtos faz emergir estratégias inovadoras de desenvolvimento de novos 
produtos, como a cooperação competitiva. No entanto, a mesma possui um impacto positivo significativo sobre o desempenho da inovação de produtos apenas quando os mecanismos de partilha de conhecimentos internos e mecanismos de proteção formais do conhecimento estão presentes (ESTRADA; FAEMS; FARIA, 2016).

Em contrapartida Trkman e Desouza (2012) refletem sobre os riscos ligados ao conhecimento. Em seu estudo apontaram exemplos de tais riscos, que refletem problemas a serem refletidos. Dentre os mesmos destaca-se o fato de que uma organização pode fazer uso do conhecimento da outra para ganhar vantagem competitiva. Isto denota a necessidade de adoção de cuidados e até acordos formais de reciprocidade. Reflete-se também que a organização com maior conhecimento pode explorar a outra parte.

O uso do conhecimento pode ser dado para comprimir as margens de lucro dos fornecedores. Isto expõe a necessidade de firmar contratos de longo prazo e buscar desenvolver investimentos em conjunto.

É citado o uso do conhecimento sobre o consumidor buscando o aumento o Market Share, sendo necessários acordos formais de divisão de lucros e volume de transações entre os participantes.

No caso das patentes, pode-se existir a comercialização de uma nova patente por uma das partes, sendo necessário a confiança, reciprocidade, acordos de propriedade intelectual, existência de espaços comuns de colaboração e experimentação.

Os autores também citam existência de casos de "roubo" de profissionais da outra parte, o uso do conhecimento compartilhado como forma de desenvolver parceiros terceiros, comercialização do conhecimento para concorrentes ou até mesmo a transferência não intencional em encontros informais. É sugerida a adoção de políticas de treinamento com atividades de socialização, com cultura organizacional adequada e regras claras, buscando a diminuição no turnover.

\section{Procedimentos metodológicos}

O estudo foi desenvolvido pela abordagem qualitativa (COLLIS; HUSSEY, 2005) para analisar como os gestores de uma empresa de conhecimento intensivo lidam com as situações que envolvem ações decisórias sobre compartilhar e proteger o conhecimento organizacional.

A organização que sediou o estudo foi criada em 1969 numa cidade do interior de São Paulo, com tradição no desenvolvimento de pesquisas para o setor sucroenergético. Na sua origem foi uma unidade de pesquisas de uma Cooperativa de Produtores de Cana-de-Açúcar, Açúcar e Álcool do Estado de São Paulo, sendo voltada ao desenvolvimento de variedades mais produtivas e melhoria da qualidade na produção dos derivados. A partir de 2004, a organização tornou-se uma associação independente, sem fins lucrativos, com o objetivo de se tornar o principal centro mundial de desenvolvimento e integração de tecnologias disruptivas da indústria 
sucroenergética, capaz de vencer o desafio de dobrar, de maneira economicamente sustentável, a taxa de inovação do setor.

Com esta mudança, seus associados aumentaram de 32 para quase 200 em 3 anos, expandindo suas atividades, até então muito concentradas nos estados de São Paulo e Paraná, para Minas Gerais, Espírito Santo, o centro-oeste e o nordeste brasileiro e em 2011 a empresa saiu da condição de sem fins lucrativos para uma organização com fins lucrativos (sociedade anônima).

Desde o início de suas operações a produtividade da cana-de-açúcar aumentou em torno de $40 \%$, com custo de produção que caiu de cerca $66 \%$. Além da sede no interior do Estado de São Paulo, existe outra unidade na Bahia e diversos polos.

A organização conta com um quadro de 350 profissionais, sendo que, dos dedicados às atividades de inovação, $60 \%$ são mestres e doutores reconhecidos em suas areas, sendo este dado uma característica singular da organização pesquisada.

A pesquisa objetivou capturar e entender a dinâmica da vida organizacional da empresa, a partir das atividades e atos formalmente estabelecidos assim como àqueles que são informais ou mesmo secretos (GODOI; MELLO; SILVA, 2010, p. 127). Trata-se de um tema com pouco conhecimento sistematizado, o que levou a definição por um estudo exploratório Yin (2010). Para o processo de coleta de dados foram adotados três instrumentos qualitativos: pesquisa documental, observação participante e, a entrevista semiestruturada. (CRESWELL, 2014; GODOI; MELLO; SILVA, 2010; SAMPIERE; COLLADO; LUCIO, 2013).

Para a pesquisa documental utilizou-se documentos internos da empresa disponibilizados pela gerência de $\mathrm{RH}$, bem como outros solicitados pelos pesquisadores, na medida em que foram citados pelos entrevistados. Consultou-se também matérias publicadas no site da organização. Os documentos consultados seguem relacionados. O nome da empresa foi substituído pela palavra "Centro" como recurso para preservar sua identificação:

a) DOC 1 - Regulamento Segurança da Informação

b) DOC 2 - Contrato de trabalho

c) DOC 3 - Termo de sigilo

d) DOC 4 - Protocolo de Intenções

e) DOC 5 - NOTICIA 220913 - Centro patrocina livro sobre Adubação da Cana

f) DOC 6 - Código Ética

g) DOC 7 - NOTICIA 290312 - Centro quer ser referência mundial

h) DOC 8 - Site do Centro. 
A entrevista se caracterizou como semiestruturada desenvolvida através de um protocolo organizado em 7 blocos de informações:

$$
\begin{aligned}
& \text { Bloco I - Identificação dos respondentes } \\
& \text { Bloco II - Atuação na empresa como gestor } \\
& \text { Bloco III - Conhecimento como diferencial competitivo } \\
& \text { Bloco IV - Compartilhamento de conhecimento } \\
& \text { Bloco V - Parcerias } \\
& \text { Bloco VI - Proteção de conhecimento } \\
& \text { Bloco VII - Decisão de proteção e compartilhamento }
\end{aligned}
$$

A seleção dos participantes da pesquisa foi definida a partir de um quadro funcional de 23 gestores distribuídos em funções de pesquisa, comerciais e administrativas. Os critérios para a constituição do corpo de participantes foram:

a) inclusão dos gestores de P\&D justificada pelo fato de eles lidarem diariamente com as questões relativas ao conhecimento organizacional;

b) inclusão da gestora de recursos humanos como representante responsável pelos colaboradores, ou seja, pelo core competence da empresa;

c) inclusão da gestora de propriedade intelectual justificada pela sua função de gerenciar os processos de proteção do conhecimento organizacional;

d) inclusão da gestora de informações responsável pelos processos de compartilhamento.

Desse modo e com a colaboração da gestora de Recursos Humanos foi definida a participação de 8 profissionais para compor a pesquisa, sendo 5 gestores de P\&D e 1 gestor de cada função, constituindo-se assim uma amostra intencional e não probabilística (SILVA; MENEZES, 2001). Em função de imprevistos, de natureza profissional, que inviabilizaram a participação de um gestor de P\&D, a amostra final foi composta de 7 gestores. As entrevistas foram gravadas e, posteriormente transcritas, conforme normas da ABNT e NURC/SP n.338 EF e 331 D2 (PRETI; URBANO, 1990). Aplicou-se na sequência a ferramenta de análise AtlasTI - versão 7.5. Após o processo de transcrição das entrevistas as mesmas foram encaminhadas a cada entrevistado acompanhadas de solicitação de validação e liberação para o estudo.

O delineamento dos trabalhos de campo foi apoiado, inicialmente, por uma revisão da literatura realizada em fontes de produção bibliográfica como: ANPAD (www.anpad.org.br); Periódicos CAPES (http://www.periodicos.capes.gov.br); base SCOPUS (http://www.scopus.com) e sites de dissertações e teses, com o objetivo 
de identificar pesquisas antecedentes sobre o assunto. 0 resultado deste procedimento reforçou-se novamente a lacuna identificada pelo estudo, bem como o desafio da construção de um desenho metodológico próprio de pesquisa. Duas referências teóricas foram selecionadas para se constituírem em suportes teóricos do estudo de campo: o Manual de Técnicas e Ferramentas de Gestão do Conhecimento (YOUNG, 2010) e o Framework proposto por Trkman e Desouza (2012).

O manual de Young (2010) foi adaptado, através de processo de simplificação (exclusão), de modo a considerar apenas as iniciativas voltadas especificamente ao compartilhamento de conhecimento e, o Framework proposto por Trkman e Desouza (2012) foi utilizado na íntegra, com pequenos ajustes para atender a especificidade da empresa.

Para a constituição do roteiro das entrevistas foram consideradas as ferramentas de método de compartilhamento de conhecimento a partir das considerações de Young (2010), que destaca a assistência de pares, revisões de aprendizado, revisões após a ação ou lições aprendidas, narrativas, espaços físicos de colaboração, café do conhecimento, comunidades de prática, taxonomia, bibliotecas de conhecimento sistema de gestão de documentos, bases de conhecimento, blogs, serviços de redes sociais, serviços de VOIP (voice over internet protocols voz pela internet), cluster de conhecimento, localizador de especialistas, espaços de colaboração virtuais, mentor, portal do conhecimento e compartilhamento de vídeo. O Quadro 4 apresenta o referencial teórico adotado para estruturar a pesquisa empírica apontando sua relação com os objetivos do estudo.

\section{Quadro 4 - Objetivos e Referencial Teórico}

\begin{tabular}{|c|c|}
\hline Objetivos Específicos & Referencial Teórico Principal \\
\hline $\begin{array}{l}\text { Identificar a importância que os gestores } \\
\text { atribuem ao conhecimento organizacional; }\end{array}$ & $\begin{array}{l}\text { Alvarenga Neto (2008) e Nonaka e Takeuchi (1997 e 2008) - Conceitos } \\
\text { de conhecimento e conhecimento organizacional } \\
\text { Barney (1991), Sveiby (1998), Shinoda (2012) e Van Der Berg (2013) - } \\
\text { Valor e diferencial do conhecimento Van Der Berg (2013) - Tipos de } \\
\text { conhecimento }\end{array}$ \\
\hline $\begin{array}{l}\text { Descrever as políticas e práticas utilizadas } \\
\text { pelos gestores para compartilhar o } \\
\text { conhecimento organizacional; }\end{array}$ & $\begin{array}{l}\text { Davenport e Prusak (1998) } \\
\text { compartilhamento } \\
\text { Choo e Alvarenga Neto (2010) }\end{array}$ \\
\hline 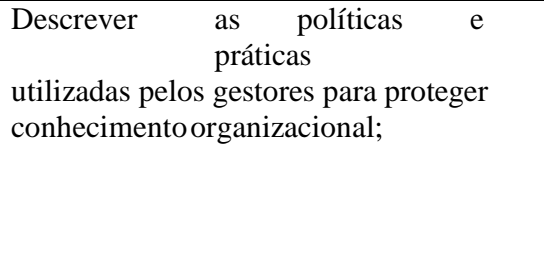 & $\begin{array}{l}\text { Kaplinsky et al. (2006) e Hurmelinna-Laukkanen (2011) - } \\
\text { Importância da proteção para projetos de P\&D Kaplinsky et al. (2006) - } \\
\text { Vetores de vazamento de conhecimento } \\
\text { Van Der Berg (2013) e Desouza e Vanapalli (2005) - Práticas e } \\
\text { ferramentas de proteção } \\
\text { Trkman e Desouza (2012) - Riscos e consequências de vazamento } \\
\text { Ritalaa et al. (2015) - Compartilhamento e vazamento. }\end{array}$ \\
\hline
\end{tabular}


Compartilhamento e Proteção do Conhecimento: um Estudo Realizado em Uma Empresa de Conhecimento Intensivo do Setor Sucroenergético
Rogerio Salles Loureiro; Daniel Basso

Polezi; Dalila Alves Corrêa; Érica

Cristiane Belon Galvão; Sergio

Ricardo Siani

Investigar os dilemas que os gestores

associam aos processos de

compartilhamento e proteção do

conhecimento.
Hurmelinna-Laukkanen

de inovação

Trkman e Desouza (2012) - Dilema em redes

Fonte: Elaborado pelos autores.

As categorias analíticas do estudo foram identificadas a priori e, ajustadas a posteriori, utilizando-se o processo de categorização semântica permitindo o agrupamento dos temas conforme recomenda Bardin (1977). O Quadro 5 apresenta as categorias analíticas do estudo após tal processo

\section{Quadro 5 - Categorização Semântica}

\begin{tabular}{|c|c|c|}
\hline Categoria & Subcategorias & Descrição da subcategoria \\
\hline \multirow{3}{*}{$\begin{array}{l}\text { a) Valor do } \\
\text { conhecimento } \\
\text { para a organização }\end{array}$} & $\begin{array}{l}\text { a1) Conceito de conhecimento e de } \\
\text { conhecimento organizacional }\end{array}$ & $\begin{array}{l}\text { Definição de conhecimento e de conhecimento } \\
\text { organizacional concebida pelos gestores }\end{array}$ \\
\hline & $\begin{array}{l}\text { a2) Conhecimento como diferencial } \\
\text { competitivo }\end{array}$ & $\begin{array}{l}\text { Concepção que os gestores tem em relação ao } \\
\text { reconhecimento do conhecimento como gerador de diferencial } \\
\text { competitivo }\end{array}$ \\
\hline & $\begin{array}{l}\text { a3) Diferencial de valor dos tipos de } \\
\text { conhecimento }\end{array}$ & $\begin{array}{l}\text { Diferenciação que os gestores fazem entre os tipos de } \\
\text { conhecimento: tácito, codificado e encapsulado }\end{array}$ \\
\hline \multirow{6}{*}{$\begin{array}{l}\text { b)Compartilhamento } \\
\text { de Conhecimento }\end{array}$} & $\begin{array}{l}\text { b1) Conceito de Compartilhamento } \\
\text { de conhecimento }\end{array}$ & $\begin{array}{l}\text { Definição de compartilhamento de conhecimento concebida } \\
\text { pelos gestores }\end{array}$ \\
\hline & $\begin{array}{l}\text { b2) Importância do } \\
\text { Compartilhamento de conhecimento }\end{array}$ & $\begin{array}{l}\text { Reconhecimento dos gestores quanto a importância do } \\
\text { compartilhamento de conhecimento na organização }\end{array}$ \\
\hline & $\begin{array}{l}\text { b3) Compartilhamento de } \\
\text { conhecimento e inovação }\end{array}$ & $\begin{array}{l}\text { Percepção dos gestores em relação ao compartilhamento de } \\
\text { conhecimento como forma de acelerar a inovação }\end{array}$ \\
\hline & $\begin{array}{l}\text { b4) Ferramentas de } \\
\text { compartilhamento de conhecimento }\end{array}$ & $\begin{array}{l}\text { Instrumentos/práticas utilizadas pelos gestores para } \\
\text { compartilhar conhecimento }\end{array}$ \\
\hline & $\begin{array}{l}\text { b5) Compartilhamento de } \\
\text { conhecimento em projetos com parceria }\end{array}$ & $\begin{array}{l}\text { Ocorrência de compartilhamento de conhecimento em } \\
\text { projetos com parcerias e como é desenvolvido. }\end{array}$ \\
\hline & $\begin{array}{l}\text { b6) Ambiente favorável ao } \\
\text { compartilhamento de conhecimento }\end{array}$ & $\begin{array}{l}\text { Indicações de que a organização incentiva as práticas de } \\
\text { compartilhamento de conhecimento }\end{array}$ \\
\hline \multirow{6}{*}{$\begin{array}{l}\text { c) Proteção de } \\
\text { Conhecimento }\end{array}$} & $\begin{array}{l}\text { c1) Conceito de Proteção de } \\
\text { Conhecimento }\end{array}$ & $\begin{array}{l}\text { Definição de proteção de conhecimento concebida pelos } \\
\text { Gestores }\end{array}$ \\
\hline & $\begin{array}{l}\text { c2) Importância da Proteção do } \\
\text { Conhecimento }\end{array}$ & $\begin{array}{l}\text { Reconhecimento dos gestores quanto a importância da } \\
\text { proteção de conhecimento na organização }\end{array}$ \\
\hline & $\begin{array}{l}\text { c3) Proteção de conhecimento e } \\
\text { inovação }\end{array}$ & $\begin{array}{l}\text { Percepção dos gestores em relação a proteção de } \\
\text { conhecimento como forma de inibir a inovação }\end{array}$ \\
\hline & $\begin{array}{l}\text { c4) Ferramentas de proteção de } \\
\text { conhecimento }\end{array}$ & $\begin{array}{l}\text { Instrumentos/práticas utilizadas pelos gestores para proteger } \\
\text { Conhecimento }\end{array}$ \\
\hline & $\begin{array}{l}\text { c5) Proteção de conhecimento em } \\
\text { projetos com parceria }\end{array}$ & $\begin{array}{l}\text { Ocorrência de proteção de conhecimento em projetos com } \\
\text { parcerias e como é desenvolvida }\end{array}$ \\
\hline & $\begin{array}{l}\text { c6) Riscos de perda de } \\
\text { conhecimento }\end{array}$ & $\begin{array}{l}\text { Percepção dos gestores quanto aos riscos e possíveis vetores } \\
\text { de vazamento de conhecimento }\end{array}$ \\
\hline d) Dilema do & $\begin{array}{l}\text { d1) Questionamento sobre } \\
\text { compartilhar e/ou proteger }\end{array}$ & $\begin{array}{l}\text { Ocorrência de incertezas por parte dos gestores quanto a } \\
\text { compartilhar e/ou proteger conhecimento }\end{array}$ \\
\hline
\end{tabular}




\begin{tabular}{l|l|l}
\hline $\begin{array}{l}\text { compartilhar e/ou proteger } \\
\text { conhecimeno }\end{array}$ & $\begin{array}{l}\text { d2) Critérios de decisões para } \\
\text { compartilhar e/ou proteger } \\
\text { conhecimento }\end{array}$ & $\begin{array}{l}\text { Definição de critérios utilizados pelos gestores para } \\
\text { decidirem sobre qual conhecimento compartilhar e qual proteger }\end{array}$ \\
\cline { 2 - 3 } & $\begin{array}{l}\text { d3) Impacto das decisões sobre } \\
\text { compartilhar e/ou proteger nos projetos } \\
\text { deP\&D }\end{array}$ & $\begin{array}{l}\text { Repercussões que os gestores identificam como decorrentes } \\
\text { das decisões sobre compartilhar e proteger conhecimento em } \\
\text { projetos de P\&D }\end{array}$ \\
\hline
\end{tabular}

Fonte: Elaborado pelos autores.

A análise dos dados foi qualitativa. Segundo Miles e Huberman (1984, p.23) esta análise é essencialmente de caráter interpretativo, a começar pelo processo de categorização e, como tal estes autores incitam os pesquisadores a atribuírem importância a esta peculiaridade. Fêz-se uso da análise de conteúdo descrita por Bardin (1977), por meio de três etapas: a pré-análise, a exploração do material e o tratamento dos resultados. O trabalho interpretativo do material empírico das entrevistas se deu a partir da categorização descritiva recomendada por Bardin (1977).

\section{Resultados e análise dos dados}

As características demográficas dos 7 participantes mostram que $57 \%$ são homens e $43 \%$ mulheres. Quanto a faixa etária, $43 \%$ tem idade acima de 50 anos, $29 \%$ entre 40 e 50 anos, $14 \%$ entre 30 e 40 e o mesmo percentual tem menos de 30 anos. No total, $72 \%$ dos participantes têm mais de 40 anos e $71 \%$ deles tem mais de 10 anos de casa, sugerindo amplo conhecimento da empresa e de seus processos.

Em relação a escolaridade observou-se que 14\% deles tem ensino superior, $72 \%$ tem especialização e $14 \%$ doutorado. Quanto a formação acadêmica, 2 são da área de Engenharia, 1 da área Química, 1 na área de Biologia e Direito, 1 da área de Agronomia, 1 da área de Psicologia e 1 da área de Biblioteconomia.

Durante o período de observação participante pode-se verificar que a especialização do grupo de profissionais é um aspecto que traz dificuldades no processo de compartilhamento e proteção do conhecimento, pois os gerentes têm que lidar com uma equipe de profissionais com formação diversificada da sua área e com nível de conhecimento superior. Com isso a tarefa de orientar e definir o que pode ou deve ser compartilhado e protegido se torna tarefa muito complexa.

Objetivando compreender como os gestores lidam com situações de compartilhamento e proteção do conhecimento, foram feitos questionamentos no sentido, de inicialmente, descrever a amostra em relação a experiência e atuação na função gerencial. Apenas um entrevistado (responsável pela área de propriedade intelectual), não gerencia diretamente uma equipe apesar de se confrontar, diariamente, com situações de gerenciamento de conhecimento. Os outros sete gestores lideram equipes com variação de amplitude entre 1 a 30 pessoas, tendo uma média de 14 profissionais por equipe. A amplitude de gestão está assim distribuída: 1 gestor com 30 subordinados; outro com 
22; outro com 17; outro com 14 subordinados; outro com 12 subordinados; outro com 01,01 gestor sem subordinados. No caso dos gestores que são responsáveis pela área de pesquisa identificou-se que estes gerenciam de 2 a 8 projetos simultaneamente.

Para a apresentação da análise das quatro categorias/subcategorias do estudo, que tratam especificamente o compartilhamento e a proteção do conhecimento optou-se pela utilização de quadros sintéticos, conforme seguem. Enquanto síntese das respostas dos gestores optou-se também por incluir destaques parciais das falas dos entrevistados.

\subsection{Categoria "A" - valor do conhecimento para a organização}

Quadro 6 - Subcategorias de valor do conhecimento para a organização

\begin{tabular}{|c|c|}
\hline $\begin{array}{l}\text { Conceito de } \\
\text { conhecimento e de } \\
\text { conhecimento } \\
\text { organizacional }\end{array}$ & $\begin{array}{l}\text { Ao descrever o seu conceito de conhecimento, cada gestor fez menção à natureza tácita } \\
\text { desse ativo com enfoque ao somatório de aquisições do indivíduo na sua trajetória de vida, de } \\
\text { escolaridade e de trabalho. Já o conhecimento explícito foi associado pelos gestores à informação: } \\
\text { "Conhecimento é uma soma de todo o aprendizado de sua vida a partir do momento que você se } \\
\text { conhece por gente... ele é próprio de cada indivíduo". "Acho que conhecimento para mim não é só } \\
\text { ter a informação. É ter a informação e o aprendizado e o que você faz com ele, aí você conhece } \\
\text { [...] o que a gente traduz como conhecimento organizacional se liga à cultura de cada } \\
\text { organizacão". }\end{array}$ \\
\hline $\begin{array}{l}\text { Conhecimento como } \\
\text { diferencial competitivo }\end{array}$ & $\begin{array}{l}\text { Apurou-se que os gestores reconhecem o conhecimento como diferencial competitivo da } \\
\text { empresa bem como o seu valor para expressar a identidade tácita da organização: "Na empresa } \\
\text { inovação e conhecimento são as palavras- chave de sua identidade". "O valor da nossa empresa, } \\
\text { na minha visão, é o conhecimento". }\end{array}$ \\
\hline $\begin{array}{l}\text { Diferenciação e } \\
\text { valorização dos tipos de } \\
\text { conhecimento }\end{array}$ & $\begin{array}{l}\text { Os conceitos de conhecimento tácito e encapsulado fornecidos pelos entrevistados mostram- } \\
\text { se como sinônimos, embora os mesmos tendo reconhecido a importância dos dois tipos como } \\
\text { essenciais e responsáveis pelo diferencial competitivo da organização: "Eu acho que o } \\
\text { conhecimento tácito é muito importante para uma empresa do tipo da nossa e o conhecimento } \\
\text { encapsulado é de extrema importância pois é onde se consegue gerar receita através dos projetos e } \\
\text { produtos que você gera, imagino que é daí que vamos ter o valor e a nossa sobrevivência". }\end{array}$ \\
\hline
\end{tabular}

Fonte: Elaborado pelos autores.

Pelas entrevistas, observou-se que os gestores classificam o conhecimento tácito - associado a pessoas, e de natureza mais intangível, como sendo o que agrega competitividade. Embora o conhecimento encapsulado em produtos também traz diferenciação. Pela análise documental não se identificou nenhuma sistematização em relação aos tipos de conhecimento existentes na organização, mostrando ausência de considerações que denotam o posicionamento da empresa sobre estes aspectos. 


\subsection{Categoria "B" - compartilhamento do conhecimento}

\section{Quadro 7 - Subcategorias de compartilhamento do conhecimento} compartilhamento de conhecimento agrega valor para ambas as partes: "Eu tenho uma informação que troco com você conhecimento $\quad$ e você agrega alguma coisa a mim e eu agrego a você" - isso é compartilhamento". Mas para os gestores de P\&D compartilhamento se associa a possibilidade de vazamento de informação: "nas parcerias tem mais chances de vazamento".

Importância do compartilhamento de conhecimento

Há concordância quanto ao compartilhamento de conhecimento ser fundamental para a geração de ideias. Identificou-se a preocupação dos entrevistados com a proteção, em especial com a possibilidade perda de conhecimento através da saída de profissionais da empresa: "Eu acho que é de extrema importância o compartilhamento de conhecimento, para você mitigar um pouco o risco de você perder alguém da equipe".

Compartilhamento de conhecimento e inovação

Os entrevistados foram unânimes em afirmar que o compartilhamento de conhecimento acelera o processo de inovação:"O compartilhamento do conhecimento é condição para acelerar a inovação, para se chegar mais rápido aos resultados".

Ferramentas de compartilhamento de conhecimento

A empresa adota várias ferramentas para compartilhamento, no entanto, nem todos os gestores fazem uso delas. As mais utilizadas são: assistência de pares, revisões de aprendizado, revisões após a ação ou lições aprendidas, narrativas, espaços físicos de colaboração, café do conhecimento, comunidades de prática, taxonomia, bibliotecas de conhecimento, bases de conhecimento, blogs, serviços de redes sociais, serviços de VOIP, cluster de conhecimento, localizador de especialistas, espaços de colaboração virtuais, mentor, portal do conhecimento, compartilhamento de vídeo, e-mail, telefone, vídeo conferência, intranet, treinamento, intercâmbio material genético.

\begin{tabular}{l|l}
\hline Compartilhamento de & Os gestores ratificaram que as parcerias na empresa são criadas com o objetivo prioritário
\end{tabular} conhecimento em projetos de parceria de alavancar a inovação através do intercâmbio de conhecimento. "Entramos com nosso Know How e eles entram com Know How deles e isso nos levam ao desenvolvimento de um produto inovador".

Ambiente favorável ao compartilhamento de conhecimento Os gestores têm opiniões similares em relação a reconhecer que o ambiente de trabalho na organização mostra-se favorável ao compartilhamento, mas que também gera competição. "O ambiente é favorável". "Eu acho que o ambiente de trabalho entre as pessoas até favorece e não cria barreiras". "Eu acho que existe, de certa forma, uma competição, mas não é prejudicial".

Fonte: Elaborado pelos autores.

Observou-se o reforço da associação do compartilhamento e proteção do conhecimento. É evidente a preocupação dos gestores com a perda de colaboradores conexa ao prejuízo do conhecimento tácito. A afirmativa é justificável pois ao compartilhar conhecimento e deixar terceiros acessar o ativo estratégico é possível diminuir o impacto da perda do profissional, mas também pode-se ampliar as possibilidades do vazamento. Tal situação é também descrita por Hurmelinna-Laukkanen (2011) de modo que no momento que questões ligadas ao compartilhamento são conectadas a preocupações de proteção é criado um contrassenso, elucidando-se um momento para tomada de decisão. 
Compartilhamento e Proteção do Conhecimento: um Estudo Realizado em Uma Empresa de Conhecimento Intensivo do Setor Sucroenergético
Rogerio Salles Loureiro; Daniel Basso

Polezi; Dalila Alves Corrêa; Érica Cristiane Belon Galvão; Sergio Ricardo Siani

\subsection{Categoria "C" - proteção de conhecimento}

\section{Quadro 8: Subcategorias de proteção de conhecimento}

\begin{tabular}{|c|c|}
\hline $\begin{array}{l}\text { Conceito de proteção de } \\
\text { conhecimento }\end{array}$ & $\begin{array}{l}\text { O sentido de "proteção" para os gestores está associado ao não compartilhamento e, } \\
\text { também à "proteção de patentes": "Trata-se de alguma ação que vai evitar que aquele } \\
\text { conhecimento seja divulgado, transferido, compartilhado". }\end{array}$ \\
\hline $\begin{array}{l}\text { Importância da proteção } \\
\text { do conhecimento }\end{array}$ & $\begin{array}{l}\text { A preocupação com a proteção do conhecimento responsável pelo diferencial } \\
\text { competitivo da empresa, é uma questão que preocupa os gestores, em especial, durante o } \\
\text { desenvolvimento de um projeto de P\&D. "Então eu diria que é importantíssimo e é muito } \\
\text { dinâmico". "Eu acho que é fundamental. A propriedade intelectual é fundamental em uma } \\
\text { empresa de P\&D" }\end{array}$ \\
\hline $\begin{array}{l}\text { Proteção do } \\
\text { conhecimento e inovação }\end{array}$ & $\begin{array}{l}\text { Embora reconheçam a importância da proteção, alguns gestores afirmam que pode inibir } \\
\text { o processo de inovação e, outros afirmam que não. "Inibe porque você cria regras e regras } \\
\text { limitam o processo criativo". "Eu acho que não inibe. Eu não acredito que impeça o } \\
\text { progresso". }\end{array}$ \\
\hline $\begin{array}{l}\text { Ferramentas de proteção } \\
\text { de conhecimento }\end{array}$ & $\begin{array}{l}\text { Várias ferramentas para apoiar o processo de proteção de conhecimento foram } \\
\text { identificadas. Dentre elas: controle de níveis de acesso à informação e proteção eletrônica, } \\
\text { termo de confidencialidade, registro de patentes, treinamento, sigilo (não divulgação), } \\
\text { regulamento de segurança de informações, contrato de trabalho com cláusula de } \\
\text { confidencialidade, política de retenção de funcionários baseada no conhecimento. }\end{array}$ \\
\hline $\begin{array}{l}\text { Proteção de } \\
\text { conhecimento em } \\
\text { projetos de parceria }\end{array}$ & $\begin{array}{l}\text { As parcerias são regidas sempre por contratos com cláusulas explícitas de } \\
\text { confidencialidade e punições para o não cumprimento destas regras. "A parceria tem vantagens } \\
\text { em relação aos demais clientes, porque ela tem contratos, e contrato passa por uma discussão } \\
\text { que engloba considerações jurídicas, penalizações, [...] via de regra em uma parceria fica } \\
\text { estabelecido o que cada um quer, isto fica documentado". }\end{array}$ \\
\hline $\begin{array}{l}\text { Riscos de perda de } \\
\text { conhecimento }\end{array}$ & $\begin{array}{l}\text { A proteção demasiada pode levar a empresa a um isolamento e, ao comprometimento da } \\
\text { vantagem competitiva. A empresa deve ter critérios sobre o que proteger - isso não é tão } \\
\text { simples de se definir. Logo o risco fica por conta da impossibilidade de proteger o } \\
\text { conhecimento que vai embora junto com o profissional que sai da empresa. Esse conhecimento } \\
\text { é facilmente transferível para os concorrentes - é nesse o contexto, que os gestores reconhecem } \\
\text { o risco da perda de proteção. "A maior possibilidade de perder o diferencial competitivo está } \\
\text { em perda de pessoas, pois é difícil de você recuperar, pois no resto você tem backup". }\end{array}$ \\
\hline
\end{tabular}

Fonte: Elaborado pelos autores.

A totalidade dos entrevistados mostrou compreensão acerca dos problemas ligados ao vazamento de conhecimento, evidenciando que o maior temor se concentra na atitude dos colaboradores, especialmente quando ocorre a saída dos mesmos da organização. Verifica-se assim, mais um contexto de valorização do conhecimento tácito para a organização, bem como impactos de perdas sobre a mesma. 


\subsection{Categoria "D" - Dilema do compartilhar e/ou proteger conhecimento}

Quadro 9 - Subcategorias sobre o dilema de compartilhar e/ou proteger conhecimento

\begin{tabular}{l|l}
\hline $\begin{array}{l}\text { Questionamento sobre } \\
\text { Compartilhar e/ou } \\
\text { Proteger }\end{array}$ & $\begin{array}{l}\text { Os entrevistados reconheceram a existência de dúvidas no processo de compartilhar e } \\
\text { proteger conhecimento. Afirmaram que, estes questionamentos ocorrem, principalmente, na } \\
\text { gestão do conhecimento tácito: "A gente tem uma preocupação grande e constante com o que } \\
\text { vai fazer e o que vai falar". "Sim, tenho sempre este tipo de dúvida, sempre". }\end{array}$ \\
\hline $\begin{array}{l}\text { Critérios de decisões para } \\
\text { compartilhar e/ou } \\
\text { proteger conhecimento }\end{array}$ & $\begin{array}{l}\text { Os relatos mostram que não existem regras definidas ou direcionadoras quanto a estas } \\
\text { decisões. Para os gestores as decisões de compartilhar/proteger ocorrem de acordo com as } \\
\text { experiências, maturidade e conhecimento de cada gestor: "Muitas vezes eu vou no meu } \\
\text { feeling[...], no que eu acho que devo fazer". "Eu me baseio nos meus conhecimentos tácitos". }\end{array}$ \\
\hline $\begin{array}{l}\text { Impacto das decisões } \\
\text { sobre compartilhar e/ou } \\
\text { proteger nos projetos de } \\
\text { P\&D }\end{array}$ & $\begin{array}{l}\text { Os gestores reconhecem que estas escolhas de compartilhar ou proteger um determinado } \\
\text { conhecimento podem atrasar o andamento dos projetos de P\&D, gerar vazamentos de } \\
\text { informação estratégica, inibir o processo criativo ou até impedir a realização de uma parceria: } \\
\text { "As decisões Influenciam, porque os projetos vão ter o andamento conforme o que líder decidir } \\
\text { praticamente, porque ele vai compartilhar conhecimento até onde ele acha que deve fazê-lo e e } \\
\text { isso pode definir a velocidade daquele projeto". "Influencia até no andamento de um projeto". }\end{array}$ \\
\hline
\end{tabular}

Fonte: Elaborado pelos autores.

Existem dificuldades por parte dos gestores para distinguir com segurança, aquilo que pode ser compartilhado e o que deve ser protegido, sendo esta situação aquela que identifica a existência de um dilema na organização envolvendo a questão do conhecimento organizacional. Possivelmente, a criação de ambientes adequados ao compartilhamento e proteção deste ativo possa oferecer aos gestores melhores condições em relação a como se comportarem diante desta situação.

\section{Considerações finais}

Conhecimento é uma fonte criadora da vantagem competitiva obtida através de processos interativos em nível intra e extra organizacionais. Trata-se portanto, de um ativo que demanda gestão. Quando esta não está consolidada o mesmo fica à mercê das iniciativas individuais dos gestores, criando situações suscetíveis à geração de conflitos e dilemas gerenciais sobre 0 que pode ser compartilhado e o que deve ser protegido. Neste contexto, a empresa deverá criar as condições capacitantes para que o compartilhamento ocorra no sentido de acelerar os processos de inovação e, ao mesmo tempo implantar ferramentas e processos de proteção, afim de salvaguardar 0 conhecimento relevantemente estratégico para a manutenção da sua vantagem competitiva.

A criação destas condições impõe desafios difíceis de superação, mas que devem ser considerados pelos diversos níveis gerenciais, pois decisões que envolvem a questão compartilhar e proteger respondem 
também pelos tipos de impactos que recairão sobre os resultados das organizações.

Preocupações sobre o compartilhamento e a proteção de conhecimento se fazem presentes no cotidiano da organização pesquisada. Sendo o conhecimento uma variável intangível ele está subjacente aos processos de trabalho dos gestores, logo não tão visível e, por isto, somente através de processos investigativos ele toma forma corpórea naquele cotidiano e pode revelar uma de suas facetas que é o dilema tratado neste artigo.

Não foi objetivo do estudo apontar soluções, procedimentos ou diretrizes que atenuassem este dilema. Buscou-se identificar e apresentar evidências empíricas, potencialmente consistentes, no sentido de levar os gestores a refletirem sobre a importância de dedicar igual atenção ao compartilhamento e a proteção do conhecimento organizacional.

Nesta linha, o estudo confirmou a complexidade do assunto, o qual estabelece relações com a criação, manutenção e/ou perda de vantagem competitiva, e impõe também tomada de decisões, muitas das quais praticadas de forma isolada e solitária já que a organização pesquisada não tem uma política definida e compartilhada pelos gestores.

O estudo apontou que mesmo fazendo uso de ferramentas de compartilhamento e proteção, são os gestores que decidem sobre qual conhecimento deve e pode ser compartilhado e/ou protegido. Fazem isto apoiando em suas experiências, intuições e vivência. A partilha do conhecimento foi positivamente destacada pelos gestores, embora expressaram preocupações em relação ao risco de seu vazamento. Esta possibilidade é corroborada por Ritalaa et al. (2015), ao comentar que o vazamento pode inibir o seu desempenho e efeito positivo. Desse modo, prevalece a experiência profissional do gestor para lidar com esta situação. Apoiar-se na experiência é algo válido para eles, porém não o suficiente para lidar com a complexidade e dilema que vivenciam. Cabe à organização elaborar políticas que definem a forma como irão tratar este ativo tão importante no contexto de seu compartilhamento e proteção. 0 atendimento desta perspectiva estaria explicitando 0 quanto 0 conhecimento organizacional é, de fato, reconhecido como um ativo estratégico para a empresa.

Finalmente, resgata-se que o objetivo principal deste trabalho foi o de contribuir para que a empresa pesquisada refletir sobre os dados e as análises aqui apresentadas. A partir disto leva-la a repensar formas de resguardar a sua vantagem competitiva, obtida através do conhecimento que gera para o setor de atuação, já que se trata de um centro de pesquisa da cana de açúcar que está na vanguarda internacional.

$\mathrm{Na}$ condição de um estudo exploratório o mesmo apresentou trilhas para sua continuidade, das quais destacamos a sua aplicação em outras instituições intensivas em conhecimento.

\section{Referências}


ALVARENGA NETO, R. C. D. de. Gestão do conhecimento em organizações: proposta de mapeamento conceitual integrativo. São Paulo: Saraiva, 2008.

ATLAS.TI. Product brochure. 2015. Disponível em: <http://www.atlasti.com/product.html>. Acesso em: 31 jul. 2017.

BARDIN, L. Análise de conteúdo. Lisboa: Edições 70, 1977.

BARNEY, J. Firm resources and sustained competitive advantage. Journal of Management, v. 17, n. 1, p. 99-120, 1991.

$\mathrm{CHAI}, \mathrm{K}-\mathrm{H}$. et al. Bridging islands of knowledge: a framework of knowledge sharing mechanisms. International Journal of Technology Management, v. 25, n. 8, p. 703-727, 2003.

CHOO, C. W. A organização do conhecimento: como as organizações usam a informação para criar significado, construir conhecimento e tomar decisões. São Paulo: Senac, 2006.

CHOO, C. W.; ALVARENGA NETO, R. C. D. de. Beyond the ba: managing enabling contexts in knowledge organizations. Journal of Knowledge Management, v. 14, n. 4, p.592-610, 2010.

COLLIS, J.; HUSSEY, R. Pesquisa em administração. Porto Alegre: Bookman, 2005.

CRESWELL, W.J. Investigação qualitativa e projeto de pesquisa. 3 ed. Porto Alegre: Penso, 2011.

DAVENPORT, T. H. Process management for knowledge work. In: HANDBOOK ON BUSINESS PROCESS MANAGEMENT 1. Introduction, methods, and information systems. Berlin: Springer Berlin Heidelberg, 2015. p. 17-35.

DAVENPORT, T. H.; PRUSAK, L. Ecologia da informação: por que só a tecnologia não basta para o sucesso na era da informação. São Paulo: Futura, 1998.

DAVENPORT, T. H.; PRUSAK, L. Conhecimento Empresarial: como as organizações gerenciam o seu capital intelectual. Rio de Janeiro: Campus, 1998.

DESOUZA, K. C.; VANAPALLI, G. K. Securing knowledge in organizations: lessons from the defense and intelligence sectors. International Journal of Information Management, v. 25, p. 85-98. 2005

DHILLON, G. et al. Deciding between information security and usability: developing value based objectives. Computers in Human Behavior, v. 61, p. 656-666, 2016.

DRUCKER, $P$. The new productivity challenge. Harvard Business Review, v. 69, n. 6, p. 69-79, Nov./Dec. 1991. 
ESTRADA, I.; FAEMS, D.; FARIA, P. de. Coopetition and product innovation performance: the role of internal knowledge sharing mechanisms and formal knowledge protection mechanisms. Industrial Marketing Management, v. 53, p. 56-65, Feb. 2016.

GODOI, C. K.; MELLO, R. B.de; SILVA, A. B. (Org.). Pesquisa qualitativa em estudos organizacionais: paradigmas, estratégias e métodos. São Paulo: Saraiva, 2010.

GRANT, R M. Toward a knowledge-based theory of the firm. Strategic management Journal, v. 17, p. 109-122, 1996.

HURMELINNA-LAUKKANEN, P. Enabling collaborative innovation: knowledge protection for knowledge sharing. European Journal of Innovation Management, v. 14, n. 3, p. 303-321, 2011.

IYER, G.; RAVINDRAN, S. Organizational commitment, knowledge management initiative importance and success likelihood as antecedents of knowledge sharing intention: an exploratory study. In: AMERICAS CONFERENCE ON INFORMATION SYSTEMS, 19., 2013. Proceedings... AMCIS 2013 - Hyperconnected World: Anything, Anywhere, Anytime, v. 4, 2013. Chicago, IL, United States, 2013. p. 2654-2659.

KAPLINSKY, R. et al. Towards a taxonomy of knowledge leakage: literature and framework. In: KNOWLEDGE AND LEARNING TRACK, BRITISH ACADEMY MANAGEMENT (BAM) CONFERENCE, Belfast, 2006. Proceedings... [s.I.: s.n.], 2006.

KOGUT, B.; ZANDER, U. Knowledge of the firm, combinative capabilities, and the replication of technology, organization science. Organization Science, v. 3, n. 3, p. 383-397, ago. 1992.

MILES, M. B.; HUBERMAN, A. M. Qualitative data analysis: a source book of new

methods. Bervely Hills, C. A.: Sage, 1984.

NAKANO, D. N.; FLEURY, A. C. C. Conhecimento organizacional: uma revisão conceitual de modelos e quadros de referência. Porto Alegre: Produto \& Produção, v. 8, n. 2, p. 11-23, jun. 2005.

NONAKA, I. The knowledge creating company. Harvard Business Review, v. 69, n. 6, p. 96-104, Nov./Dec. 1991.

NONAKA, I.; TAKEUCHI, H. Criação de conhecimento na empresa: como as empresas japonesas geram a dinâmica da inovação. Rio de Janeiro: Campus, 1997.

NONAKA, I.; TAKEUCHI, H. Gestão do conhecimento. Porto Alegre: Bookman, 2008.

POLANYI, M. The tacit dimension. London: Routledge and Kegan Paul, 1966. 
POPADIUK, S.; RICCIARDI. G. Conversão do conhecimento é fonte de Vantagem Competitiva Sustentável? Uma análise empírica sob a perspectiva da Resource- based View. Gestão \& Produção, São Carlos, v. 18, n. 1, 2011. p. 193-204.

OLIVEIRA, L. R et al. Análise do papel da segurança na gestão do conhecimento organizacional. In: ENCONTRO DE ADMINISTRAÇÃO DA INFORMAÇÃO - ENANPAD, 4., 2013, Bento Gonçalves. Anais... Bento Gonçalves: ANPAD, 2013. Disponível em: <http://www.anpad.org.br/diversos/trabalhos/EnADI/enadi_2013/2013_E nADI95.pdf >. Acesso em: 31 jul. 2017.

PORTER, M. E. The contributions of industrial organization to strategic management. Academy of management review, v. 6, n. 4, p. 609-620, 1981.

PRAHALAD, C. K.; HAMEL, G. The core competence of the corporation. Harvard Business Review, v. 68, n. 3, p. 3-15, maio/jun. 1990.

PRETI, D.; URBANO, H. (Org). A linguagem falada culta na cidade de São Paulo. São Paulo: T. A. Queiro; Fapesp, 1990. v. 4.

RITALAA, $P$. et al. Knowledge sharing, knowledge leaking and relative innovation performance: an empirical study. Technovation, v. 35, p. 2231, Jan. 2015.

ROJKO, K.; LESJAK, D.; VEHOVAR, V. Information communication technology spending. in (2008-) economic crisis. Industrial Management and Data Systems, v. 111, n. 3, p. 391-409, 2011.

SAMPIERI, H. R.; COLLADO, F. C.; LUCIO, B. P. M. Metodologia de pesquisa. 5. ed. Porto Alegre: Penso, 2013.

SHINODA, A. C. M. Gestão do conhecimento em projetos: um estudo sobre conhecimentos relevantes, fatores influenciadores e práticas em organizações projetizadas. 2012. $298 \mathrm{f}$. Dissertação (Mestrado) Faculdade de Economia, Administração e Contabilidade da Universidade de São Paulo, 2012.

SILVA, E. L. da.; MENEZES, E. M. Metodologia da pesquisa e elaboração de dissertação. Florianópolis: Laboratório de Ensino a Distância da UFSC, 2001.

STEWART, T. A. Capital intelectual. Rio de Janeiro: Campus,1998.

SVEIBY, K. E. Nova riqueza das organizações: gerenciando e avaliando patrimônios do conhecimento. Rio de Janeiro: Campus, 1998.

TEIXEIRA, E. D. et al. A importância das políticas, controles, compartilhamento e conformidades legais sobre a segurança do conhecimento. In: Simpósio de Gestão da Inovação Tecnológica - ANPAD, XXVII, 2012. Salvador: ANPAD, 2012. Disponível em: 
<http://www.anpad.org.br/diversos/trabalhos/Simp\%C3\%B3sio/simposio _2012/2012_SIMPOSIO135.pdf>. Acesso em: 29 jul. 2017.

TONET, $H$. O desafio de compartilhar e disseminar conhecimento nas organizações In: ANGELONI, M.T.(Org). Gestão do conhecimento no Brasil: casos, experiências e práticas de empresas privadas. Rio de Janeiro: Qualitymark, 2008. v.1, p.45-56.

TRKMAN, P.; DESOUZA, K. D. Knowledge risks in organizational networks: an exploratory framework. Journal of Strategic Information Systems, v. 21, p.1-17, 2012.

VAN DEN BERG, H. A. Three shapes of organizational knowledge. Journal of Knowledge Management, v. 17, n. 2, p.159-174, 2013.

YIN, R. K. Estudo de caso: planejamento e métodos. Porto Alegre: Bookman, 2010.

YOUNG, R. Knowledge management tools and techniques manual. Hirakawacha, Chiyoda-Ku, Tokyo: Asian Productivity Organisation, 2010. 